\title{
Acquired thrombotic thrombocytopenic purpura with isolated CFHR3/1 deletion-rapid remission following complement blockade
}

\author{
Martin Bitzan ${ }^{1}$ (D) $\cdot$ Rawan M. Hammad ${ }^{1} \cdot$ Arnaud Bonnefoy $^{2} \cdot$ Watfa Shahwan Al Dhaheri ${ }^{1,3} \cdot$ Catherine Vézina $^{4}$. \\ Georges-Étienne Rivard ${ }^{2}$
}

Received: 2 January 2018 / Revised: 27 March 2018 / Accepted: 2 April 2018 /Published online: 4 May 2018

(C) The Author(s) 2018

\begin{abstract}
Background Thrombotic thrombocytopenic purpura (TTP) is caused by the abundance of uncleaved ultralarge von Willebrand factor multimers (ULvWF) due to acquired (autoantibody-mediated) or congenital vWF protease ADAMTS13 deficiency. Current treatment recommendations include plasma exchange therapy and immunosuppression for the acquired form and (fresh) frozen plasma for congenital TTP.

Case-diagnosis/treatment A previously healthy, 3-year-old boy presented with acute microangiopathic hemolytic anemia, thrombocytopenia, erythrocyturia and mild proteinuria, but normal renal function, and elevated circulating sC5b-9 levels indicating complement activation. He was diagnosed with atypical hemolytic uremic syndrome and treated with a single dose of eculizumab, followed by prompt resolution of all hematological parameters. However, undetectably low plasma ADAMTS13 activity in the pretreatment sample, associated with inhibitory ADAMTS13 antibodies, subsequently changed the diagnosis to acquired TTP. vWF protease activity normalized within 15 months without further treatment, and the patient remained in long-term clinical and laboratory remission. Extensive laboratory workup revealed a homozygous deletion of CFHR3/1 negative for anti-CFH antibodies, but no mutations of ADAMTS13, (other) alternative pathway of complement regulators or coagulation factors.

Conclusions This case, together with a previous report of a boy with congenital TTP (Pecoraro et al. Am J Kidney Dis 66:1067, 2015), strengthens evolving in-vitro and ex-vivo evidence that ULvWF interferes with complement regulation and contributes to the TTP phenotype. Comprehensive, prospective complement studies in patients with TTP may lead to a better pathophysiological understanding and novel treatment approaches for acquired or congenital forms.
\end{abstract}

Keywords ADAMTS13 - Atypical hemolytic uremic syndrome - Complement factor H-related protein · Eculizumab · Thrombotic microangiopathy · Ultra-large von Willebrand factor multimers

Martin Bitzan

martin.bitzan@mcgill.ca

1 Division of Nephrology, Department of Pediatrics, Montreal Children's Hospital, McGill University Health Centre, Room B RC.6651, Montreal, Québec H4A 3J1, Canada

2 Service d'hématologie-oncologie, CHU Sainte-Justine and Université de Montréal, Montréal, Canada

3 Present address: Department of Pediatric, Tawam Hospital, Al Ain, United Arab Emirates

4 Division of Hematology/Oncology, Department of Pediatrics, Montreal Children's Hospital, McGill University Health Centre, Montreal, Canada

\section{Abbreviations}

ADAMTS13

AH50

aHUS

APC

aTTP

$\mathrm{CFH}$

CFHR

CFI

CH50
A disintegrin and metalloprotease with a thromboSpondin type 1 motif, member 13

Alternative pathway of complement hemolytic activity

atypical hemolytic uremic syndrome

Alternative pathway of

complement

Acquired thrombotic

thrombocytopenic purpura

Complement factor $\mathrm{H}$

Complement factor H-related protein

Complement factor I

Classical pathway of complement

hemolytic activity 


\begin{tabular}{|c|c|}
\hline DEAP HUS & $\begin{array}{l}\text { Deficiency of CFHR proteins and } \\
\text { CFH autoantibody positive } \\
\text { (anti-CFH antibody HUS) }\end{array}$ \\
\hline сTTP & $\begin{array}{l}\text { Congenital thrombotic } \\
\text { thrombocytopenic purpura }\end{array}$ \\
\hline ELISA & Enzyme-linked immune assay \\
\hline FRETS-VWF73 & $\begin{array}{l}\text { Fluorescence resonance energy } \\
\text { transfer assay with synthetic } \\
73 \text {-aminoacid peptide }\end{array}$ \\
\hline $\mathrm{Hb}$ & Hemoglobin \\
\hline HUS & Hemolytic uremic syndrome \\
\hline $\mathrm{IgG}$ & Immunoglobulin $\mathrm{G}$ \\
\hline MAC & Membrane attack complex \\
\hline PLEX & Plasma exchange \\
\hline sMAC & Soluble (circulating) MAC \\
\hline TMA & Thrombotic microangiopathy \\
\hline TTP & $\begin{array}{l}\text { Thrombotic thrombocytopenic } \\
\text { purpura }\end{array}$ \\
\hline $\begin{array}{l}\text { ULvWF } \\
\text { vWF }\end{array}$ & $\begin{array}{l}\text { Ultra-large vWF } \\
\text { von Willebrand factor }\end{array}$ \\
\hline
\end{tabular}

\section{Introduction}

Thrombotic microangiopathies (TMA) comprise a heterogeneous group of hereditary and acquired disorders characterized by microangiopathic hemolytic anemia, thrombocytopenia, and organ damage associated with capillary and arteriolar thrombosis and, in many instances, vessel wall abnormalities [1]. Thrombotic thrombocytopenic purpura (TTP) results from deficient von Willebrand factor (vWF) cleaving zinc metalloprotease ADAMTS13 [2]. $\mathrm{vWF}$ is released from Weibel-Palade bodies in vascular endothelial cells and platelet alpha granules and participates in platelet adhesion and aggregation especially in conditions of high-shear stress [3]. ADAMTS13 controls the hemostatic function of endothelial cell- and platelet-derived VWF by cleaving hyper adhesive ultra-large vWF multimers (ULvWF) [2,3]. Abundance of uncleaved ULvWF multimers leads to occlusive microthrombi in small blood vessels [1.3]. TTP can be congenital, due to homozygous or compound heterozygous mutations of ADAMTS13 (Upshaw-Schulman syndrome) or acquired (aTTP) [4]. The latter is caused by inhibitory ADAMTS13 antibodies [2,4]. Diminished metalloprotease activity below $10 \%$ of normal differentiates TTP from other forms of TMA [1,4]. Intensive plasma exchange (PLEX) therapy combined with immunosuppression has improved the previously dismal outcome of aTTP $[2,4]$.

Complement-mediated haemolytic uremic syndrome (HUS), commonly referred to as "atypical" (aHUS), is caused by mutations of genes encoding regulatory proteins of the alternative pathway of complement (APC) or the coagulation cascade [5]. Ten to $20 \%$ of cases are due to inhibitory autoantibodies, predominantly against complement factor $\mathrm{H}$ (CFH), associated with biallelic deletions of $C F H R 3 / 1$ ("DEAP HUS," deficiency of CFHR proteins and CFH autoantibody positive) [6]. Uncontrolled APC activation results in the formation of membrane attack complex (MAC), endothelial injury, and a prothrombotic phenotype. However, the etiological diagnosis of TMA can be challenging, particularly where diagnostic assays are not readily available. aHUS is effectively treated with the anti-C5 antibody eculizumab [7,8], while PLEX and immunosuppression are recommended for patients with autoimmune (DEAP) HUS [7], similar to aTTP [2,4].

Here we present a 3-year-old boy with an eventual diagnosis of aTTP who recovered promptly after a single dose of eculizumab. The case challenges the accepted diagnostic and therapeutic dichotomy between (atypical) HUS and TTP.

\section{Case report}

A previously healthy 3-year-old Moroccan boy was admitted with anemia and thrombocytopenia. He had been well until 3 weeks prior to presentation, when he developed a febrile erythematous rash. Fever recurred a week before admission, associated with lethargy, vomiting, and non-bloody diarrhea. Family history is negative for kidney or hematological disorders; the non-consanguineous parents and the boy's three siblings are healthy.

The patient appeared pale, with bruises on abdomen, back, and lower extremities. The clinical exam was otherwise unremarkable. Laboratory work-up revealed hemolytic anemia with marked reticulocytosis, presence of schistocytes, profound thrombocytopenia, elevated uric acid, and normal serum creatinine concentrations. Plasma haptoglobin was undetectable, lactate dehydrogenase (LDH) elevated, and direct Coombs test negative. A stool sample was negative for E. coli $\mathrm{O} 157: \mathrm{H} 7$. Anti-streptolysin titers were only marginally elevated. D-dimers were increased to $2.49 \mu \mathrm{g} / \mathrm{mL}$ fibrinogenequivalent units (N 0.02-0.47 $\mu \mathrm{g} / \mathrm{mL})$. Prothrombin, international normalized ratio (INR), partial thromboplastin time, fibrinogen, and $\mathrm{C} 3$ and $\mathrm{C} 4$ concentrations were normal, and sC5b-9 was increased to $653 \mathrm{ng} / \mathrm{mL}$ (normal $<300 \mathrm{ng} / \mathrm{mL}$; SC5b-9 Plus MicroVue, ELISA, TECOmedical/Quidel, San Diego, CA). Urinalysis revealed microscopic erythrocyturia and mild proteinuria. On Day 2, the patient received transfusions of red blood cells and platelets. Hemoglobin $(\mathrm{Hb})$ continued to fall to $48 \mathrm{~g} / \mathrm{L}$, and platelets dropped to $5 \times 10^{9} / \mathrm{L}$ within 2 days of the transfusions (Table 1).

A tentative diagnosis of aHUS was made, and a single dose of eculizumab $\left(\sim 900 \mathrm{mg} / \mathrm{m}^{2}\right)$ was given 2 days after admission. The patient was vaccinated against $N$. meningitidis and started amoxicillin prophylaxis. Platelet count, $\mathrm{Hb}$, and LDH started to improve after 4 days and normalized within 17 days. The diagnosis was corrected to TTP several days after 
Table 1 Biological parameters pre- and post-anti-C5 antibody infusion ${ }^{\mathrm{a}}$

\begin{tabular}{|c|c|c|c|c|c|c|}
\hline Parameter $^{a}$ & Reference range & Presentation & Peak/nadir & $\begin{array}{l}\text { Pre- } \\
\text { eculizumab }\end{array}$ & Resolution ${ }^{\mathrm{b}}$ & Last measurement \\
\hline Hemoglobin & $105-135 \mathrm{~g} / \mathrm{L}$ & $60(\mathrm{D}-1)$ & $48(\mathrm{D}-1)$ & $74^{c}$ & $108(\mathrm{D}+17)$ & $125(\mathrm{D}+1494)$ \\
\hline $\begin{array}{l}\text { Serum lactate } \\
\quad \text { dehydrogenase (LDH) }\end{array}$ & $142-297 \mathrm{U} / \mathrm{L}$ & $1205(\mathrm{D}-1)$ & $1205(\mathrm{D}-1)$ & 926 & $285(\mathrm{D}+17)$ & $211(\mathrm{D}+1494)$ \\
\hline Haptoglobin & $0.69-1.96 \mathrm{~g} / \mathrm{L}$ & $<0.06(\mathrm{D}-1)$ & $<0.06(\mathrm{D}-1 /+17)$ & $<0.06$ & $0.36 / 0.89(\mathrm{D}+59 / 82)$ & $0.83(\mathrm{D}+1494)^{\mathrm{d}}$ \\
\hline Reticulocytes & $\begin{array}{l}0.002-0.020 \\
\times 10^{9} / \mathrm{L}\end{array}$ & NA & $0.116(\mathrm{D}-0)$ & 0.116 & $0.018(\mathrm{D}+12 / 17)$ & $0.012(\mathrm{D}+521)$ \\
\hline Platelet count & $\begin{array}{l}140-450 \\
\times 10^{9} / \mathrm{L}\end{array}$ & $8(\mathrm{D}-1)$ & $5(\mathrm{D}+1)$ & $21^{\mathrm{c}}$ & $202(\mathrm{D}+17)$ & $311(\mathrm{D}+1494)$ \\
\hline $\mathrm{eGFR}^{\mathrm{e}}$ & $\mathrm{mL} / \mathrm{min} / 1.73 \mathrm{~m}^{2}$ & $110(\mathrm{D}-1)$ & $110(\mathrm{D}-1)$ & 113 & $139(\mathrm{D}+10)$ & $122(\mathrm{D}+1301)$ \\
\hline ADAMTS $13^{\mathrm{f}}$ & $56-133 \%$ & NA & $\begin{array}{l}<10 \\
(\mathrm{D}-0 /+17)\end{array}$ & $<10$ & $<10 / 47(D+17 / 82)^{f}$ & $>150(\mathrm{D}+1301)$ \\
\hline Anti-ADAMTS13 & Negative & NA & $1: 64(\mathrm{D}-0)$ & $1: 64$ & $\begin{array}{l}\text { 1:4/negative } \\
\quad(D+360 / 475)\end{array}$ & $\begin{array}{l}\text { negative } \\
\qquad(\mathrm{D}+942 / 1304)\end{array}$ \\
\hline $\mathrm{C} 3$ & $0.75-1.40 \mathrm{~g} / \mathrm{L}$ & NA & $0.85(\mathrm{D}-0)$ & 0.85 & NA & $1.37(\mathrm{D}+1494)$ \\
\hline $\mathrm{C} 4$ & $0.17-0.47 \mathrm{~g} / \mathrm{L}$ & NA & $0.35(\mathrm{D}-0)$ & 0.35 & NA & $0.39(\mathrm{D}+1494)$ \\
\hline $\mathrm{CH} 50$ & $69-129 \%$ & $87(\mathrm{D}-0)$ & $<1(\mathrm{D}+1)^{\mathrm{g}}$ & 87 & $9 / 79(\mathrm{D}+31 / 59)^{\mathrm{g}}$ & $103(\mathrm{D}+528)$ \\
\hline AH50 & $30-113 \%$ & $42(\mathrm{D}-0)$ & $<1(\mathrm{D}+1)^{\mathrm{g}}$ & 42 & $29 / 76(\mathrm{D}+59 / 82)^{\mathrm{g}}$ & $78(\mathrm{D}+528)$ \\
\hline sC5b-9 & $<300 \mathrm{ng} / \mathrm{mL}$ & NA & $653^{\mathrm{h}}(\mathrm{D}-0)$ & 653 & $262(\mathrm{D}+81 / 360)$ & $106(\mathrm{D}+1301)^{\mathrm{h}}$ \\
\hline Anti-CFH antibody & Negative & Negative & Negative & Negative & Negative & Negative \\
\hline $\begin{array}{l}\text { Urine protein } \\
\text { (dipstick) }\end{array}$ & Negative $(g / L)$ & $0.3(\mathrm{D}-1)$ & $0.3(\mathrm{D}-1)$ & NA & $\operatorname{Neg}(D+1)$ & $\operatorname{Neg}(D+1301)$ \\
\hline $\begin{array}{l}\text { Urine blood/hemoglobin } \\
\text { (dipstick) }\end{array}$ & Negative & Moderate $(\mathrm{D}-1)$ & Moderate $(D-1 /+2)$ & NA & $\begin{array}{l}\text { Small/negative } \\
(\mathrm{D}+5 / 6)\end{array}$ & negative $(+1301)$ \\
\hline U protein/creatinine & $<0.020 \mathrm{~g} / \mathrm{mmol}$ & NA & $0.050(\mathrm{D}+5)$ & NA & $0.021(\mathrm{D}+6)$ & $0.012(\mathrm{D}+1301)$ \\
\hline Urine RBC (microscopy) & Per HPF & $25-30(\mathrm{D}-0)$ & $25-30(\mathrm{D}-0)$ & $25-30$ & Negative $(D+6)$ & Negative $(\mathrm{D}+1301)$ \\
\hline
\end{tabular}

$D$ day (relative to eculizumab infusion), $e G F R$ estimated glomerular filtration rate, $H P F$ high-power field, $N A$ not available/not applicable, $R B C$ red blood cells

a See text for additional laboratory results. " $D$ " (day) refers to the number of days before or after eculizumab infusion ("D 0" indicates the day of infusion, " $\mathrm{D}-0$ " immediately prior to infusion)

${ }^{\mathrm{b}}$ Resolution documented on the second of the two indicated days (where interim measurements were not obtained)

${ }^{\mathrm{c}}$ After transfusion of packed red blood cells and platelets

${ }^{\mathrm{d}}$ Haptoglobin peaked after recovery at $2.89(\mathrm{D}+523)$

${ }^{\mathrm{e}} \mathrm{Schwartz}$ (CKiD) formula

${ }^{f}$ Fluorescence resonance energy transfer (FRETS-VWF73) assay

${ }^{\mathrm{g}}$ Eculizumab-induced complement blockade

${ }^{\mathrm{h}}$ Intermittent rise of plasma sC5b-9 concentration to $530 \mathrm{ng} / \mathrm{mL}$ was incidentally detected more than $2 \frac{1}{2}$ years after initial presentation (see Fig. 1 and Discussion)

discharge from hospital, when the ADAMTS13 activity in the pre-treatment plasma sample was found to be unmeasurably low using the fluorescence resonance energy transfer (FRETS-VWF73 substrate) assay (Peptide International Inc. Louisville KY) [9]. The patient also had anti-ADAMTS13 IgG antibodies (1:64) (in-house titration ELISA with recombinant ADAMTS-13 (Baxter, Mississauga, Canada) as target antigen and serial plasma dilutions). Incubating patient and reference plasma (ADAMTS13 activity 0 and 100\%, respectively) in equal volumes at $37{ }^{\circ} \mathrm{C}$ for 30 min reduced the ADAMTS13 activity in the mixture to $0 \%$, indicating the presence of an inhibitor in an assay analogous to the Bethesda assay using the FRETS-VWF73 substrate. Due to rapid clinical and laboratory improvement following treatment with eculizumab, we refrained from PLEX and immunosuppressive therapy. ADAMTS13 activity normalized completely after 15 months (Fig. 1 and Table 1).

The initial mutation screen for ADAMTS13 and genes encoding complement factors $\mathrm{CFH}$, CFI, and CFB, CD46/ membrane cofactor protein (MCP), factor H-related protein (CFHR) 5, C3, apelin and thrombomodulin was negative. $\mathrm{CFH}$ protein concentration was normal. Comprehensive retesting confirmed the previous results and excluded mutations of diacylglycerol kinase-epsilon (DGKE), plasminogen (PLG) and methylmalonic aciduria and homocystinuria, cblC complementation type (MMACHC), but identified a homozygous deletion of $C F H R 3 / 1$. No anti-CFH antibodies were demonstrated during active disease and follow-up, and there was no 


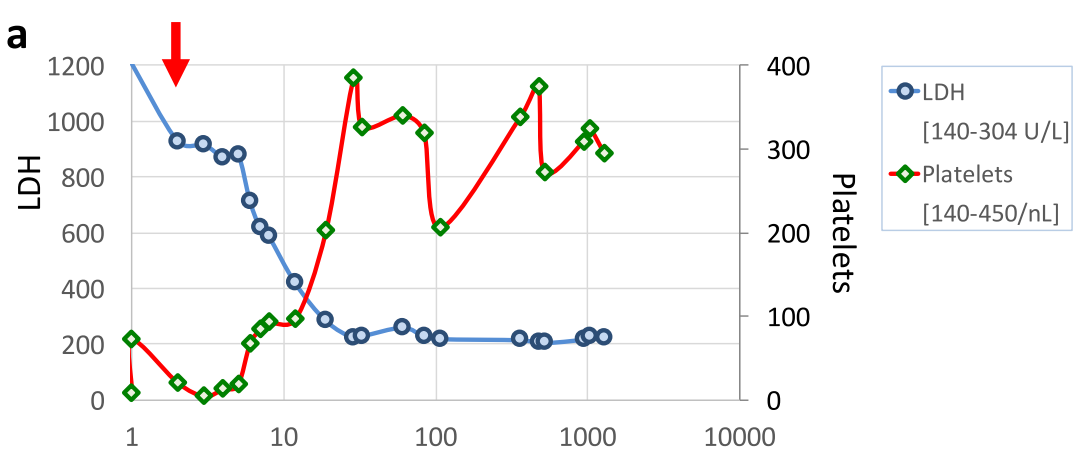

b

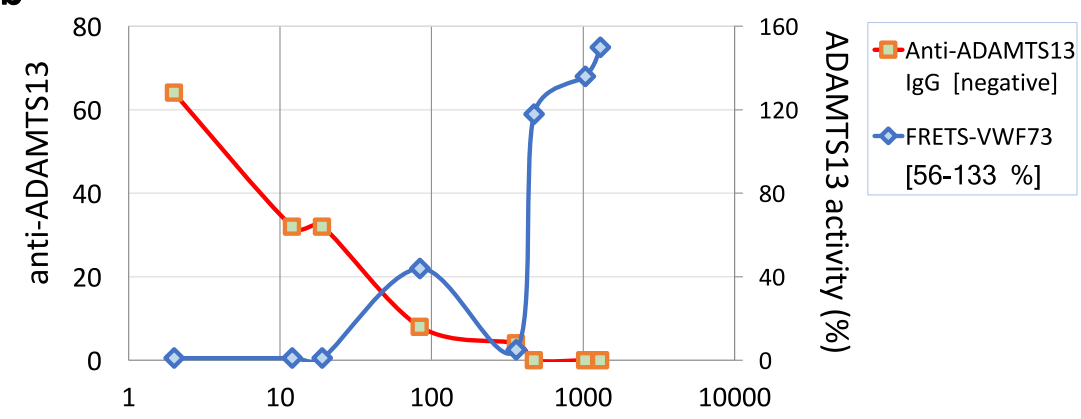

C

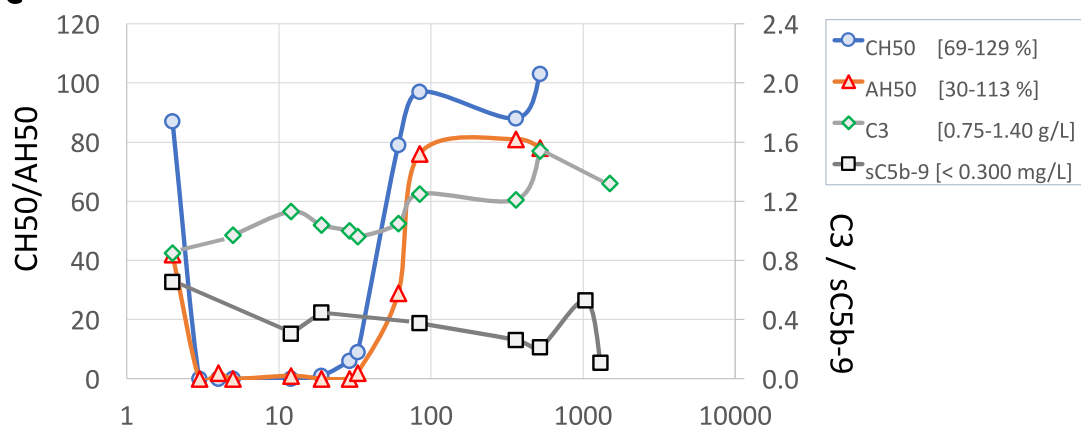

Days after admission

Fig. 1 Disease course a Platelet count and lactate dehydrogenase (LDH) levels pre- and post-therapy. Eculizumab was given on Day 2 of admission (red arrow). The platelet count increased steadily from $5 \times 10^{9} / \mathrm{L}$ on Day 3 and normalized 17 days after the antibody infusion, similar to LDH and hemoglobin ( $108 \mathrm{~g} / \mathrm{L}$ on day 17 of eculizumab therapy; not shown). b

documented relapse of TTP or TMA over the 4 years of observation. A moderate, temporary increase of plasmatic sC5b-9 was noted $>2 \frac{1}{2}$ years after presentation in the absence of clinical symptoms or hematological evidence of TMA. At the time, ADAMTS13 activity had normalized, and anti-CFH antibodies were undetectable (Table 1 and Fig. 1).

\section{Discussion}

We report a young boy with acquired TTP, with nonmeasureable ADAMTS13 activity and elevated, inhibitory anti-ADAMTS13 antibodies. He had no neurological signs,
ADAMTS13 activity and anti-ADAMTS13 antibodies following eculizumab infusion. c Results of global classical (CH50) and alternative pathway activities (AH50), C3 and soluble MAC (sC5b-9) concentrations during acute disease and long-term follow-up

and apart from erythrocyturia and mild proteinuria, renal function remained normal throughout the disease course. The case is noteworthy because of documented complement activation and swift clinical and laboratory resolution following treatment with eculizumab, without PLEX or immunosuppressive therapy.

The differentiation between TTP and aHUS can be challenging [10-12]. Our patient was found to have a homozygous deletion of $C F H R 3 / 1$ without detectable anti-CFH antibodies. Deletions in the CHFR3/1 locus have been noted in 5-8\% of the healthy population, with wide ethnic diversity [13], and are believed to be of no consequence in the absence of anti-CFH antibodies [6,14]. At present, a link between CFHR deletion and TTP has not been formally established. However, it has 
been speculated that lack of CFHR expression predisposes to autoimmune diseases [15]. Interestingly, we documented retrospectively a second "silent" rise of plasma sC5b-9 concentrations long after the resolution of TTP, without apparent hemolysis and thrombocytopenia and in the absence of anti-CFH autoantibodies (Fig. 1). We posit that intermittent or abortive episodes of APC activation and SMAC formation occur in predisposed individuals, depending on stimulus type and intensity [16]. While increased levels of sC5b-9 indicate that the terminal complement cascade has been activated, we do not know what triggered this biological event $2 \frac{1}{2}$ years after the initial presentation, and the current literature does not provide an answer concerning the frequency and specificity of increased sC5b-9 measurements or what constitutes an indication for treatment. By way of analogy, Page et al. [17] recently reported that TTP patients experience clinically uneventful episodes of diminished ADAMTS13 activity $<10 \%$ during periods of disease remission. Comprehensive and prospective, functional studies are needed to better understand the biological and clinical importance of these observations. Likewise, the temporary increase of ADAMTS13 (FRETS-VWF73) activity on day 84 of admission, confirmed in repeat assays, was unexpected in view of still detectable anti-ADAMTS13 antibodies and remains unexplained. In contrast, the documented normalization of FRETS-VWF73 assay results 15 months after disease onset correlated well with the disappearance of anti-ADAMTS13 antibodies (Fig. 1, panel B).

There is evolving experimental and ex vivo evidence of complement activation and dysregulation in TTP. For example, Turner and Moake [18] described the assembly and activation of complement by endothelial cell-anchored ULvWF molecules in vitro. Reti et al. demonstrated increased plasma concentrations of sC5b-9 and C3a in a series of patients with aTTP [19]. Plasma from TTP patients was found to contain significantly higher levels of complementcoated endothelial microparticles than controls [20]. The latter authors also showed C3 deposition on vWF-platelet strings and primary glomerular endothelial cells exposed to plasma from TTP patients in vitro, under shear. These and other studies [21-23] suggested that cleaved vWF serves as a cofactor for CFI to cleave $\mathrm{C} 3 \mathrm{~b}$ to $\mathrm{iC} 3 \mathrm{~b}$, alone or in the presence of $\mathrm{CFH}$, while ULvWF lacks cofactor activity toward CFI or CFH and permits APC activation $[21,22]$. The concept that ULvWF binds $\mathrm{C} 3 \mathrm{~b}$ and acts as a platform for the assembly of $\mathrm{C} 3 / \mathrm{C} 5$ convertase has been recently confirmed and expanded using plasma from a series of patients with congenital as well as acquired TTP [24].

Pecoraro et al. first described a 12-year-old boy with cTTP due to a compound heterozygous ADAMTS13 mutation, who was successfully treated with eculizumab [11]. This patient, too, was initially misdiagnosed to have aHUS, and eculizumab induced prompt remission. Unlike our scenario, Pecoraro's patient had severe acute kidney injury requiring dialysis. The authors also noted moderately increased plasma sC5b-9 concentrations. Renal function recovered quickly after anti-complement therapy, but TTP recurred with its discontinuation. Subsequent relapses reverted promptly with single doses of eculizumab. Pecoraro's patient had no detectable complement factor mutations nor anti-CHF or antiADAMTS13 antibodies, albeit the number of genes tested was limited and did not include CFHR3/1 [11].

In conclusion, complement activation, likely due to ULvWF-induced APC dysregulation, may contribute to the pathophysiology and clinical manifestations of TTP, especially hemolysis and likely, thrombocytopenia. The potential role of isolated CFHR3/1 deletion without detectable anti-CFH antibodies is incompletely understood. The present case and a previous report [11] suggest that anti-complement agents may have a role in the management of (some) patients with TTP, congenital, or acquired. While we are currently not advocating for complement blocking therapies in all TTP patients, we wish to highlight the merits of additional basic and clinical research beyond present guidelines. Different nosological entities as currently defined [25] may overlap, and comprehensive functional and genetic studies are needed to avoid diagnostic pitfalls, such as the presence of complement regulator mutations and/or anti-CFH antibodies [10,12,26], particularly in patients presenting with a complicated or protracted course of TTP. The pathophysiological role of dyregulated APC activation in TTP should be addressed in prospective studies.

Acknowledgments We thank Caroline Dubois for performing the antiCFH and sC5b-9 assays.

We also thank Dr. Bethany Foster, Paule Comtois, RN, and other health professionals for their help in the patient's care.

Genetic testing for ADAMTS13 was performed at Prevention Genetics (Marshfield, Wisconsin, USA), and for complement genes at the Molecular Genetics Laboratory, The Hospital for Sick Children (Toronto, Ontario) and the Molecular Otolaryngology and Renal Research Laboratories (University of Iowa, Iowa City, IA, USA). ADAMTS13, anti-ADAMTS13, anti-CFH antibody, and sC5b-9 measurements were performed in the laboratory of the Service d'hématologie-oncologie, CHU Sainte-Justine (Montréal, Québec). Additional samples were tested in the Institute of Immunology (University of Heidelberg, Germany) and the Centre hospitalier universitaire Laval (Québec, Québec).

\section{Compliance with ethical standards}

Conflict of interest $\mathrm{AB}$ and $\mathrm{MB}$ received honoraria from Alexion Pharmaceuticals, Inc. The remainder of the authors has no potential conflicts of interest to declare.

Open Access This article is distributed under the terms of the Creative Commons Attribution 4.0 International License (http:// creativecommons.org/licenses/by/4.0/), which permits unrestricted use, distribution, and reproduction in any medium, provided you give appropriate credit to the original author(s) and the source, provide a link to the Creative Commons license, and indicate if changes were made. 


\section{References}

1. George JN, Nester CM (2014) Syndromes of thrombotic microangiopathy. N Engl J Med 371:1847-1848

2. Sadler JE (2017) Pathophysiology of thrombotic thrombocytopenic purpura. Blood 130:1181-1188

3. Lenting PJ, Christophe OD, Denis CV (2015) von Willebrand factor biosynthesis, secretion, and clearance: connecting the far ends. Blood 125:2019-2028

4. Joly BS, Coppo P, Veyradier A (2017) Thrombotic thrombocytopenic purpura. Blood 129:2836-2846

5. Vieira-Martins P, El Sissy C, Bordereau P, Gruber A, Rosain J, Fremeaux-Bacchi V (2016) Defining the genetics of thrombotic microangiopathies. Transfus Apher Sci 54:212-219

6. Jozsi M, Licht C, Strobel S, Zipfel SL, Richter H, Heinen S, Zipfel PF, Skerka C (2008) Factor H autoantibodies in atypical hemolytic uremic syndrome correlate with CFHR1/CFHR3 deficiency. Blood $111: 1512-1514$

7. Loirat C, Fakhouri F, Ariceta G, Besbas N, Bitzan M, Bjerre A, Coppo R, Emma F, Johnson S, Karpman D, Landau D, Langman CB, Lapeyraque AL, Licht C, Nester C, Pecoraro C, Riedl M, van de Kar NC, Van de Walle J, Vivarelli M, Fremeaux-Bacchi V, International HUS (2016) An international consensus approach to the management of atypical hemolytic uremic syndrome in children. Pediatr Nephrol 31:15-39

8. Greenbaum LA, Fila M, Ardissino G, Al-Akash SI, Evans J, Henning P, Lieberman KV, Maringhini S, Pape L, Rees L, van de Kar NC, Vande Walle J, Ogawa M, Bedrosian CL, Licht C (2016) Eculizumab is a safe and effective treatment in pediatric patients with atypical hemolytic uremic syndrome. Kidney Int 89:701-711

9. Kokame K, Nobe Y, Kokubo Y, Okayama A, Miyata T (2005) FRETS-VWF73, a first fluorogenic substrate for ADAMTS13 assay. Br J Haematol 129:93-100

10. Tsai E, Chapin J, Laurence JC, Tsai HM (2013) Use of eculizumab in the treatment of a case of refractory, ADAMTS13-deficient thrombotic thrombocytopenic purpura: additional data and clinical follow-up. Br J Haematol 162:558-559

11. Pecoraro C, Ferretti AV, Rurali E, Galbusera M, Noris M, Remuzzi G (2015) Treatment of congenital thrombotic thrombocytopenic Purpura with Eculizumab. Am J Kidney Dis 66:1067-1070

12. Sasapu A, Cottler-Fox M, Motwani P (2017) Acquired thrombotic thrombocytopenic purpura and atypical hemolytic uremic syndrome successfully treated with eculizumab. Proc (Bayl Univ Med Cent) 30:182-183

13. Hageman GS, Hancox LS, Taiber AJ, Gehrs KM, Anderson DH, Johnson LV, Radeke MJ, Kavanagh D, Richards A, Atkinson J, Meri S, Bergeron J, Zernant J, Merriam J, Gold B, Allikmets R, Dean M, Group AMDCS (2006) Extended haplotypes in the complement factor $\mathrm{H}(\mathrm{CFH})$ and $\mathrm{CFH}$-related (CFHR) family of genes protect against age-related macular degeneration: characterization, ethnic distribution and evolutionary implications. Ann Med 38: 592-604

14. Dragon-Durey MA, Blanc C, Marliot F, Loirat C, Blouin J, SautesFridman C, Fridman WH, Fremeaux-Bacchi V (2009) The high frequency of complement factor H related CFHR1 gene deletion is restricted to specific subgroups of patients with atypical haemolytic uraemic syndrome. J Med Genet 46:447-450

15. Noone D, Al-Matrafi J, Tinckam K, Zipfel PF, Herzenberg AM, Thorner PS, Pluthero FG, Kahr WH, Filler G, Hebert D, Harvey E, Licht C (2012) Antibody mediated rejection associated with complement factor h-related protein $3 / 1$ deficiency successfully treated with eculizumab. Am J Transplant 12:2546-2553

16. Teoh CW, Riedl M, Licht C (2016) The alternative pathway of complement and the thrombotic microangiopathies. Transfus Apher Sci 54:220-231

17. Page EE, Kremer Hovinga JA, Terrell DR, Vesely SK, George JN (2016) Clinical importance of ADAMTS13 activity during remission in patients with acquired thrombotic thrombocytopenic purpura. Blood 128:2175-2178

18. Turner NA, Moake J (2013) Assembly and activation of alternative complement components on endothelial cell-anchored ultra-large von Willebrand factor links complement and hemostasis-thrombosis. PLoS One 8:e59372

19. Reti M, Farkas P, Csuka D, Razso K, Schlammadinger A, Udvardy ML, Madach K, Domjan G, Bereczki C, Reusz GS, Szabo AJ, Prohaszka Z (2012) Complement activation in thrombotic thrombocytopenic purpura. J Thromb Haemost 10:791-798

20. Tati R, Kristoffersson AC, Stahl AL, Rebetz J, Wang L, Licht C, Motto D, Karpman D (2013) Complement activation associated with ADAMTS13 deficiency in human and murine thrombotic microangiopathy. J Immunol 191:2184-2193

21. Rayes J, Roumenina LT, Dimitrov JD, Repesse Y, Ing M, Christophe O, Jokiranta TS, Halbwachs-Mecarelli L, BorelDerlon A, Kaveri SV, Fremeaux-Bacchi V, Lacroix-Desmazes S (2014) The interaction between factor $\mathrm{H}$ and VWF increases factor $\mathrm{H}$ cofactor activity and regulates VWF prothrombotic status. Blood 123:121-125

22. Feng S, Liang X, Kroll MH, Chung DW, Afshar-Kharghan V (2015) von Willebrand factor is a cofactor in complement regulation. Blood 125:1034-1037

23. Noone DG, Riedl M, Pluthero FG, Bowman ML, Liszewski MK, Lu L, Quan Y, Balgobin S, Schneppenheim R, Schneppenheim S, Budde U, James P, Atkinson JP, Palaniyar N, Kahr WH, Licht C (2016) Von Willebrand factor regulates complement on endothelial cells. Kidney Int 90:123-134

24. Bettoni S, Galbusera M, Gastoldi S, Donadelli R, Tentori C, Sparta G, Bresin E, Mele C, Alberti M, Tortajada A, Yebenes H, Remuzzi G, Noris M (2017) Interaction between multimeric von Willebrand factor and complement: a fresh look to the pathophysiology of microvascular thrombosis. J Immunol 199:1021-1040

25. Cataland SR, Holers VM, Geyer S, Yang S, Wu HM (2014) Biomarkers of terminal complement activation confirm the diagnosis of aHUS and differentiate aHUS from TTP. Blood 123:37333738

26. Chapin J, Weksler B, Magro C, Laurence J (2012) Eculizumab in the treatment of refractory idiopathic thrombotic thrombocytopenic purpura. Br J Haematol 157:772-774 